\title{
БИОЛОГИЧЕСКАЯ ОБРАТНАЯ СВЯЗЬ КАК ТЕХНОЛОГИЯ АДАПТАЦИИ К ИСПОЛЬЗОВАНИЮ ПРОТЕЗОВ ПРИ АМПУТАЦИИ НИЖНИХ КОНЕЧНОСТЕЙ
}

\author{
(C) Никишина В.Б. ${ }^{1}$, Петраш Е.А. ${ }^{1}$, Лукьянов В.В. ${ }^{2}$ \\ ${ }^{1}$ Курский государственный медицинский университет, Курск; \\ ${ }^{2}$ Курский государственный университет, Курск \\ E-mail: petrash@mail.ru
}

\begin{abstract}
В статье представлено исследование адаптации к использованию протезов пациентов с ампутацией нижних конечностей в параметрах общей чувствительности, болевой чувствительности, а также физиологических проявлений (показателей артериального давления, частоты сердечных сокращений, частоты дыхания). В результате исследования установлено, что применение технологии БОС-тренинга позволяет снизить как общую, так и отдельно болевую чувствительность у пациентов с ампутацией нижних конечностей (с ампутацией ведущей ноги, неведущей ноги, обеих нижних конечностей), повышая порог болевой чувствительности. Применение биологической обратной связи как технологии адаптации к использованию протезов при ампутации нижних конечностей позволяет повысить эффективность социального функционирования данной категории пациентов.

Ключевые слова: ампутация нижних конечностей, биологическая обратная связь, БОС-тренинг, общая чувствительность, болевая чувствительность, физиологические проявления.
\end{abstract}

\section{BIOLOGICAL FEEDBACK AS A TECHNOLOGY OF ADAPTATION TO USING PROSTHESIS AFTER AMPUTATION OF LOWER LIMBS Nikishina V.B. ${ }^{l}$, Petrash E.A. ${ }^{l}$, Lukyanov $V . V .^{2}$ \\ ${ }^{1}$ Kursk State Medical University, Kursk; ${ }^{2}$ Kursk State University, Kursk}

The article presents the study of adaptation to the use of prostheses in patients with amputation of lower limbs in parameters of general sensitivity, pain sensitivity, as well as physiological manifestations (indices of arterial pressure, heart rate, respiratory rate). As a result of the study, it was established that the use of BOS-training technology allows to reduce both general and painful sensitivity alone in patients with amputation of lower extremities (with amputation of the leading leg, the nonleading leg, both lower limbs), raising the threshold of pain sensitivity. The use of biofeedback as a technology of adaptation to using prostheses after amputation of lower extremities makes it possible to increase the effectiveness of the social functioning of this category of patients.

Keywords: amputation of lower extremities, biological feedback, BOS-training, general sensitivity, pain sensitivity, physiological manifestations.

В настоящее время численность пациентов, перенесших ампутацию нижних конечностей, составляет $10 \%$ от общего числа больных с заболеваниями костно-мышечной системы [8]. Наиболее частыми причинами ампутации являются последствия сосудистых заболеваний (атеросклеротическая гангрена) и эндокринных заболеваний (диабетическая стопа), что в общей сложности составляет более 95\% от общего числа ампутаций. При инвариантности причин (ишемия сосудов нижних конечностей, вызванная атеросклерозом, некротические процессы, опухолевые заболевания, травмы, боевые ранения и их последствия) установлено, что после ампутации нижних конечностей в 30-35\% случаев развивается болевой или фантомно-болевой синдром $[2,3$, $6,7,12]$. Во всех случаях типичной является проблема адаптации к использованию протезов, что особенно актуально при глубокой ампутации (на уровне бедра) $[6,7,10]$.

Процент пациентов с ампутацией нижних конечностей трудоспособного возраста возраста- ет [7]. В их случае использование протезов является основным способом социально-психологической адаптации. Традиционно мето-дами адаптации пациентов с ампутацией нижних конечностей являются терапевтические, исполь-зование тренажеров, методы статокинетической коррекции. Субъективными причинами отказа от использования протезов являются жалобы на болевые ощущения в здоровой конечности, фантомные боли, а также боли в области сердца (и др. вегетативные проявления). Исследо-вательских ссылок на использование метода биологической обратной связи (БОС) для адаптации к протезам при ампутации нижних конечностей в системе Elibrary и Scopus не найдено (по запросу «метод биологической обратной связи в адаптации к использованию протезов»). Основной функционал метода связан с формированием у пациентов с ампутацией нижних конечностей навыков саморегуляции и ориентировочной основы действий на их основе. Саморегуляция нервно-мышечной активности позволяет контролировать мышечное 
напряжение как моторное основание двигательной реакции, с одной стороны, с другой стороны, кинестетическую основу организации движений.

Целью исследования является изучение динамики нейрофизиологических показателей у пациентов с ампутацией нижних конечностей при адаптации к протезам с использованием технологии биологической обратной связи.

\section{МАТЕРИАЛЫ И МЕТОДЫ ИССЛЕДОВАНИЯ}

Исследование осуществлялось на базе ФГУП «Курское протезно-ортопедическое предприятие» в стационаре сложного протезирования. В исследовании приняли участие 38 человек (20 мужчин и 18 женщин) в возрасте от 42 до 68 лет (средний возраст - 54,63 44,45). Критерием включения пациентов в программу исследования являлась глубина ампутации: у всех пациентов нижняя конечность ампутирована на уровне голени. Формирование исследовательских групп для реализации программы исследования осуществлялось по двум основаниям: первым основанием являлся профиль латеральной организации (все пациенты являлись праворукими с левополушарным профилем латеральной организации); вторым основанием послужило количество ампутированных конечностей. В первую экспериментальную группу $\left(Э_{1}\right)$ вошли 16 пациентов с ампутацией неведущей ноги (ампутация правой ноги на уровне голени); вторую экспериментальную группу (Э $)_{2}$ составили 13 пациентов с ампутацией ведущей ноги (ампутация левой ноги на уровне голени). В контрольную группу (К) включались пациенты с ампутацией обеих ног на уровне голени (9 пациентов). У всех пациентов отсутствовали в анамнезе нарушения мозгового кровообращения и заболевания головного мозга. Исследование осуществлялось на условиях информированного согласия.

В соответствии с задачами исследования методы были дифференцированы по двум группам: психодиагностические методы и методы психологического воздействия. В группу диагностических методов вошли: методы исследования чувствительности (набор функциональных нейропсихологических проб); методы исследования субъективной оценки болевых ощущений; методы оценки физиологических реакций (частота сердечных сокращений, артериальное давление, частота дыхания).

Исследование чувствительности осуществлялось с применением комплекса нейропсихологических проб: проба на исследование локализации прикосновений, проба Тойбера, проба на перенос прикосновения с одной руки на другую, оценка дискриминационной чувствительности (тест Вебера) [1].

Объективная оценка нижнего абсолютного порога болевой чувствительности осуществлялась с помощью прессальгометрии. На плечо пациента надевалась манжетка, на внутренней поверхности которой был укреплен игольчатый аппликатор, и при нагнетании в нее воздуха у пациента возникало болевое ощущение. Порог болевой чувствительности оценивался по давлению в манжетке (в мм рт.ст.) в момент восприятия боли. Исследование субъективной оценки болевых ощущений осуществлялась с помощью методики А.Ш. Тхостова «Выбор дескрипторов интероцептивных ощущений» [9], а также визуальной аналоговой шкалы (ВАШ) для субъективной оценки интенсивности боли [11].

Для оценки физиологических показателей использовались: сфигмоманометрия (измерение артериального давления), исследование пульса на лучевой артерии (измерение частоты сердечных сокращений), пневмография (измерение частоты дыхания).

В качестве метода психологического воздействия был использован аппарат биологической обратной связи (БОС) «Реакор». Аппарат БОС представляет собой систему, состоящую из блока пациента, персонального компьютера (ПК) и пакета программ БОС-тренинга. Процедура применения аппарата предполагает одновременную регистрацию до 4-х физиологических сигналов в произвольном сочетании из набора: кожно-гальванические реакции (КГР); электроэнцефалография (ЭЭГ); реоэнцефалография (РЭГ); электрокардиография (ЭКГ); электромиография (ЭМГ); огибающая ЭМГ; фотоплетизмограмма (ФПГ); верхнее и нижнее дыхание; температура. Типовые места размещения датчиков определяются при выборе необходимой процедуры, сохраняются в описании процедуры и доступны при проведении анализа.

Количественная и качественная обработка полученных данных осуществлялась с помощью статистических методов (показатели средних тенденций, непараметрический U-критерий оценки значимости различий Манна-Уитни, непараметрический критерий $\chi^{2}$ Фридмана).

Организация исследования включала в себя несколько последовательных этапов. На предварительном этапе с целью формирования исследовательских групп по критерию ампутации ведущей - неведущей ноги осуществлялась оценка профиля латеральной организации головного мозга с использованием функциональных нейропсихологических проб на определение моторной асимметрии (ведущей принималась рука, которой 
пациент выполнял обозначенные инструкцией действия).

Задачей первого этапа основного исследования являлась оценка исходного уровня показателей общей и болевой чувствительности, а также физиологических показателей на этапе адаптации к протезу до начала занятий с использованием аппарата БОС (до психологического воздействия) у трех групп пациентов методом попарного сравнения.

На втором этапе - экспериментальном - осуществлялась оценка динамики (изменения) показателей общей и болевой чувствительности, а также физиологических реакций при использовании аппарата БОС по каждой группе испытуемых до и после завершения курса занятий. На этапе адаптации к протезам пациентов с ампутацией нижних конечностей применялись следующие процедуры: 1) вводная ОЭМГ (уменьшение общего и психоэмоционального напряжения, тревоги путем снижения избыточной мышечной активности; коррекция двигательных нарушений центрального и периферического характера различного генеза); 2) релаксация по ОЭМГ; 3) поддержание баланса 2-х мышц (для бучения навыкам поддержания баланса 2-х симметричных мышц на фоне их релаксации; 4) синкенезия (снижение тонуса мышц, неадекватно вовлеченных в двигательный акт); 5) болевой синдром (процедура предназначена для снижения выраженности болевого синдрома за счет уменьшения избыточного и устойчивого гипертонуса одноименных мышечных групп); 6) реципрокность (регуляция напряжения мышцагонистов и оптимизация тонуса мышц антагонистов, вовлеченных в двигательный акт).

Завершающим этапом исследования решалась задача оценки значимости различий показателей общей и болевой чувствительности, а также физиологических реакций после завершения курса занятий с использованием аппарата БОС у трех групп пациентов между собой методом попарного сравнения.

\section{РЕЗУЛЬТАТЫ ИССЛЕДОВАНИЯ И ИХ ОБСУЖДЕНИЕ}

На первом этапе исследования в результате объективного исследования порога болевой чувствительности с использованием метода

прессальгометрии было установлено, что значения нижнего абсолютного порога болевой чувствительности у пациентов с ампутацией нижних конечностей при попарном сравнении значимо не отличаются и соответствуют: при ампутации ведущей ноги $\mathrm{x} \pm \sigma=244,59 \pm 54,29$, при ампутации неведущей ноги $\mathrm{x} \pm \sigma=241,16 \pm 48,28$, при ампутации обеих ног $\mathrm{x} \pm \sigma=246,61 \pm 54,12$.

При исследовании субъективной оценки интенсивности болевых ощущений у пациентов с ампутацией нижних конечностей с использованием опросника Визуальной аналоговой шкалы установлено, что у всех испытуемых преобладающей является оценка, соответствующая в количественном выражении 6-8 баллам, качественно описываемая как сильная (таблица 1).

При исследовании дескрипторов интрацептивных ощущений методикой «Выбор дескрипторов интрацептивных ощущений» у пациентов с ампутацией обеих нижних конечностей выявлено значимое увеличение общего количества дескрипторов с преобладанием болезненных, часто встречающихся ощущений (рисунок 1).

Анализ лингвосемантического означивания болевых ощущений у пациентов с ампутацией нижних конечностей осуществлялся посредством оценки дескрипторов интрацептивных ощущений. По критерию «сенсорного ощущения боли» у пациентов с ампутацией неведущей ноги преобладают зудящие, дергающие, глубинные, жгучие, режущие и кинжальные ощущения боли; у пациентов с ампутацией ведущей ноги преобладает пронзающая, ноющая, стреляющая, монотонная, поверхностная боль; у пациентов с ампутацией обеих нижних конечностей преобладают скребущие, зудящие, стреляющие, глубинные, кусающие ощущения боли. Профиль лингвосемантического означивания по критерию эмоционального отношения к боли характеризуется: у пациентов с ампутацией неведущей ноги преобладанием беспокоящей, мучающей и надоедливой боли; у пациентов с ампутацией ведущей ноги мешающей, беспокоящей, выматывающей, мучающей, надоедливой, угнетающей, изводящей, жуткой, пугающей, тяжкой, истязающей боли; у пациентов с ампутацией обеих нижних конечностей преобладанием мешающей, мучающей, надоедливой, терзающей, тягостной, жуткой, опостылевшей, истязающей боли (рисунок 2).

Таблица 1

Показатели долевого распределения пациентов с ампутацией нижних конечностей по показателям субъективной оценки интенсивности болевых ощущений

\begin{tabular}{|c|c|c|c|c|c|c|}
\hline \multirow{2}{*}{ Качественно-количественная оценка } & \multicolumn{2}{|r|}{$Э_{1}$} & \multicolumn{2}{|r|}{$Э_{2}$} & \multicolumn{2}{|r|}{$\mathrm{K}$} \\
\hline & $\%$ & $\mathrm{X} \pm \sigma$ & $\%$ & $\mathrm{x} \pm \sigma$ & $\%$ & $\mathrm{x} \pm \sigma$ \\
\hline Сильная боль (6-8 баллов) & 82 & $6,57 \pm 0,39$ & 84 & $6,29 \pm 0,83$ & 74 & $6,94 \pm 1,37$ \\
\hline Очень сильная, нестерпимая боль (9-10 баллов) & 18 & $8,84 \pm 1,05$ & 16 & $8,51 \pm 1,26$ & 26 & $8,94 \pm 1,12$ \\
\hline
\end{tabular}




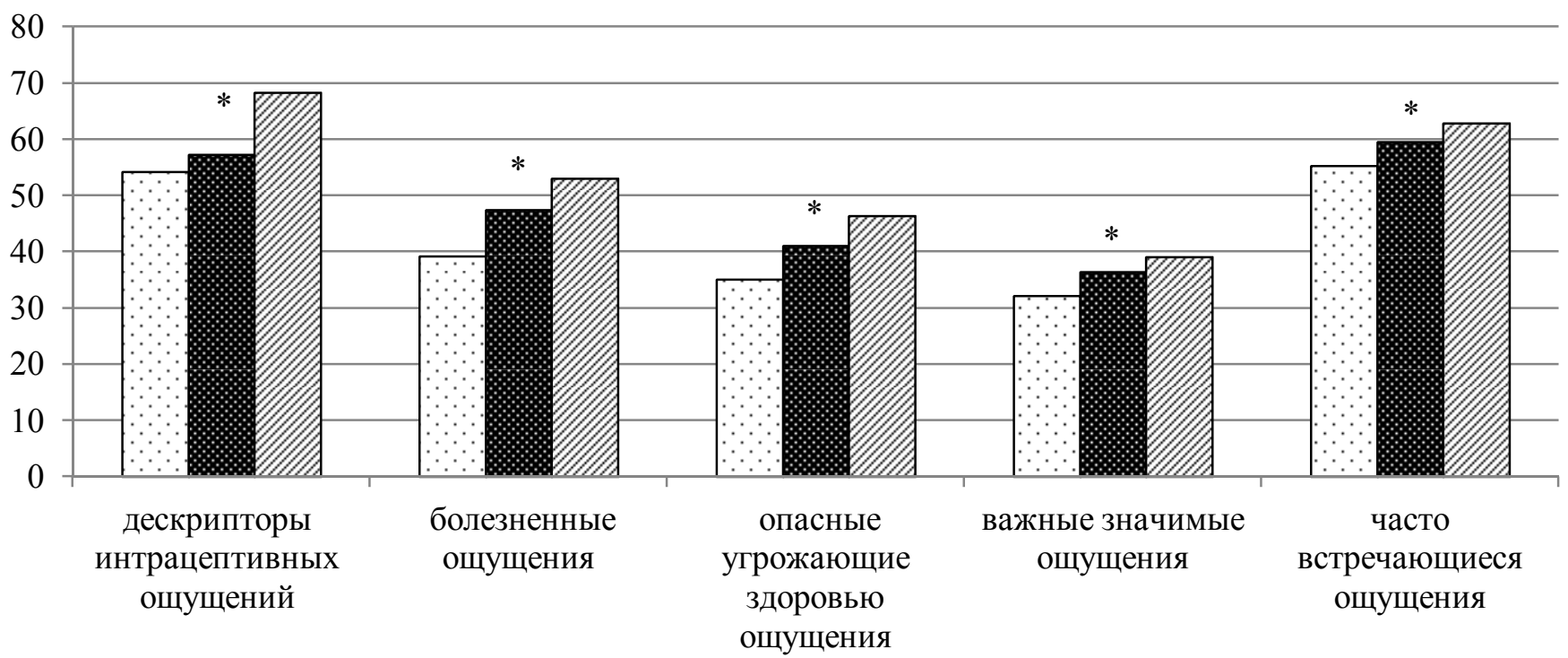

๑Пациенты с ампутацией невеедущей ноги

군нты с ампутацией ведущей ноги

ఐПациенты с ампутацией обеих нижних конечностей

Рис 1. Гистограмма частот значений дескрипторов интрацептивных ощущений у пациентов с ампутацией нижних конечностей.

При исследовании экстероцептивной чувствительности у пациентов с ампутацией нижних конечностей получены результаты, указывающие на значимое повышение чувствительности у пациентов с ампутацией ведущей ноги в сравнении с пациентами, у которых ампутирована неведущая нога $(\mathrm{p}=0,037)$, а также у пациентов $\mathrm{c}$ ампутацией ведущей ноги в сравнении с пациентами с ампутацией обеих нижних конечностей $(\mathrm{p}=0,021)$. При исследовании локализации прикосновений установлено, что у пациентов с ампутацией неведущей ноги точность локализации прикосновений определяется в границах до 10 мм в $62,5 \%$ случаев; у пациентов с ампутацией ведущей ноги определяется в тех же границах у 76,9\% пациентов; у 77,78\% пациентов с ампутацией обеих нижних конечностей точность локализации прикосновений также определяется в границах до 10 мм при допустимой норме до 15 мм.

При выполнении пробы Тойбера феномен игнорирования в тактильной сфере у пациентов с ампутацией нижних конечностей не выявлен, о чем свидетельствуют полученные результаты: пациенты с ампутацией неведущей ноги не фиксируют второе прикосновение (при одновременном прикосновении к обеим ногам) в $6,25 \%$ случаев; пациенты с ампутацией ведущей ноги не фиксируют второе прикосновение в $7,69 \%$ случаев; пациенты с ампутацией обеих нижних конечностей не фиксируют второе прикосновение в $11,11 \%$ случаев.

При исследовании переноса прикосновения с одной ноги на другую установлено, что большинство пациентов с ампутацией нижних конечностей указывают перенесенное прикосновение с точностью до 5 мм: при ампутации неведущей ноги - в $81,25 \%$ случаев; при ампутации ведущей ноги - 84,6\%; при ампутации обеих нижних конечностей $-88,89 \%$. При этом показатели диапазона нормы точности переноса прикосновений составляют до 10 мм.

Оценка дискриминационной чувствительности, определяемая как минимальное расстояние, при одновременном прикосновении к участку кожи, при котором пациент воспринимает данное прикосновение как две различные точки, осуществлялась с использованием циркуля Вебера. В норме при прикосновении одновременно двумя браншами циркуля на поверхности голени человек воспринимает отдельно два прикосновения, если расстояние между браншами 40,5 2,5 мм. При оценке дискриминационной чувствительности пациенты воспринимают два прикосновения отдельно при расстоянии между браншами циркуля до 15 мм при ампутации неведущей ноги в $56,25 \%$ случаев; при ампутации ведущей ноги в $76,90 \%$ случаев; при ампутации обеих нижних конечностей в $77,78 \%$ случаев.

Обобщая результаты исследования чувствительности у пациентов с ампутацией нижних конечностей, установлено: проявление повышенной экстероцептивной чувствительности как при точности локализации прикосновений, так и при переносе прикосновения с одной ноги на другую, a также высокий уровень дискриминационной чувствительности следует рассматривать в качестве фактора, затрудняющего процесс адаптации к использованию протезов. 


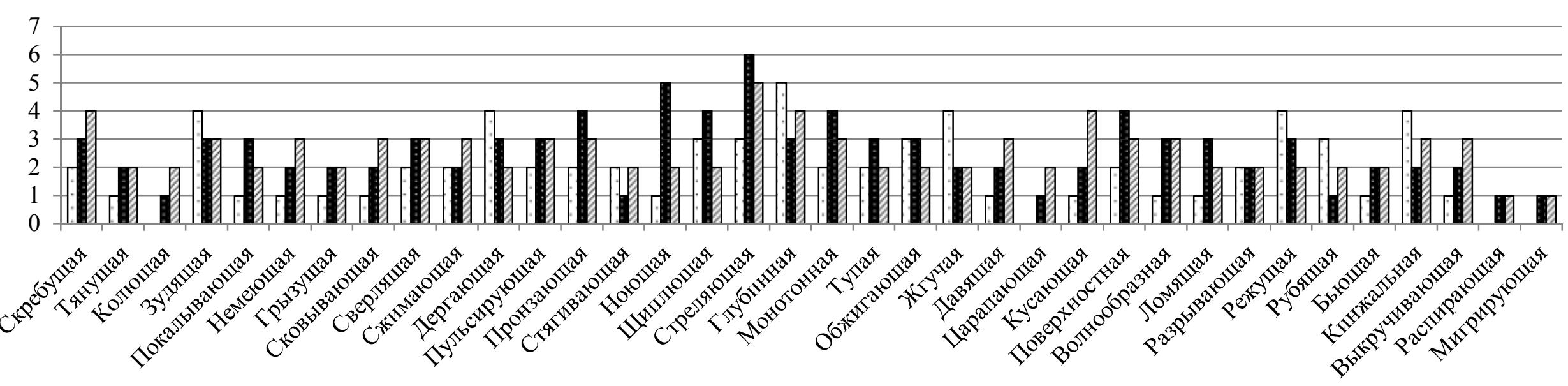

曰Пациенты с ампутацией неведущей ноги 国Пациенты с ампутацией ведущей ноги ФПациенты с ампутацией обеих нижних конечностей

В. Эмоциональное отношение к боли

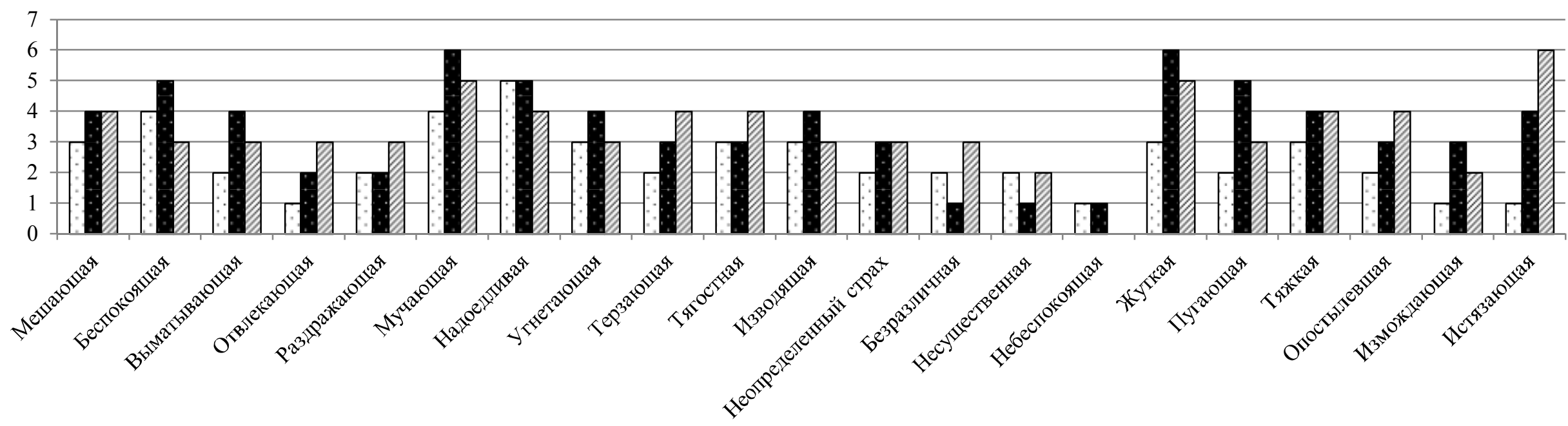

๑Пациенты с ампутацией неведущей ноги 国Пациенты с ампутацией ведущей ноги ■ациенты с ампутацией обеих нижних конечностей

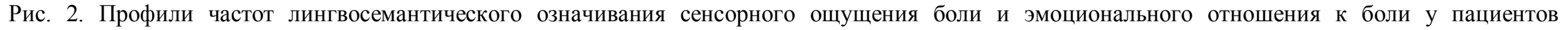
с ампутацией нижних конечностей. 
В результате исследования показателей физиологических реакций у пациентов с ампутацией ведущей ноги, пациентов с ампутацией неведущей ноги, а также пациентов с ампутацией обеих ног, выявлено незначительное повышение показателей артериального давления, частоты сердечных сокращений и частоты дыхания относительно нормативных значений на 10-20 единиц. Статистически значимых различий при попарном сравнении групп испытуемых не выявлено.

В результате исследования показателей общей и болевой чувствительности у пациентов с ампутацией нижних конечностей выявлены следующие особенности: во-первых, выявлено снижение порога болевой чувствительности при повышении интенсивности как объективного показателя порога болевой чувствительности, так и субъективной оценки интенсивности болевых ощущений. Во-вторых, у пациентов с ампутацией нижних конечностей выявлено повышение общей чувствительности (в показателях локализации, пространственного переноса и дискриминационной чувствительности). В-третьих, установлено, что общее количество выбираемых дескрипторов интрацептивных ощущений как на уровне сенсорного ощущения боли, так и эмоционального отношения к боли максимально выражено при ампутации обеих нижних конечностей; пациенты с ампутацией нижних конечностей характеризуются точной дифференциацией дескрипторов болевых ощущений и эмоционального отношения. Установлено, что чем выше интенсивность болевых ощущений, тем ниже дифференциация сенсорного ощущения боли, тем выше значимость и дифференцированность эмоционального отношения к боли. Установлено нарастание выявленных нарушений у пациентов с ампутацией ведущей ноги в сравнении с пациентами с ампутацией неведущей ноги, а также у пациентов с ампутацией ведущей ноги в сравнении с пациентами с ампутацией обеих нижних конечностей.

На экспериментальном этапе исследования осуществлялось экспериментальное воздействие: по истечении не менее 12 месяцев после ампутации на этапе реабилитации адаптация к протезу осуществлялась с использованием пакета программ БОС-тренинга. Процедуры БОС-тренинга реализуются на основе принципа «физиологического зеркала», что позволяет пациенту в буквальном смысле видеть и слышать изменения своего состояния, проявляющиеся в изменениях различных физиологических процессов.

С целью адаптации к использованию протезов БОС-тренинг включал в себя следующие процедуры: вводная ОЭМГ; релаксация по ОЭМГ; поддержание баланса 2-х мышц; синкенезия; снижение болевого синдрома; реципрокность. Для каж- дого пациента формировалась индивидуальная программа. Каждая индивидуальная программа включала в себя 12 занятий (периодичность проведения - через день) продолжительностью 30-40 мин каждое. Организация каждого занятия включала в себя две процедуры БОС-тренинга, последовательность и количество которых определялись индивидуально.

После завершения программы БОС-тренинга осуществлялась повторная диагностика показателей общей и болевой чувствительности, а также физиологических проявлений по группам испытуемых.

Полученные результаты указывают на значимое снижение интенсивности болевых ощущений при повышении нижнего абсолютного порога болевой чувствительности, снижении проявлений гиперчувствительности, а также изменении физиологических проявлений после завершения программы БОС-тренинга в процессе адаптации к протезам у всех трех групп испытуемых (таблица 2).

Применение технологии БОС-тренинга при адаптации пациентов с ампутацией нижних конечностей к использованию протезов позволяет снизить общую чувствительность на уровне бедра как на сохранной, так и на ампутированной конечности вне зависимости и, как следствие, снизить интенсивность болевой чувствительности и количество дескрипторов интрацептивных ощущений вне зависимости от того, ампутирована одна (ведущая или неведущая) или обе нижние конечности. Снижение чувствительности позволяет снизить физические ощущения дискомфорта при использовании протеза, тем самым облегчая процесс (приспособления) привыкания к нему. Снижение физиологических проявлений (снижение показателей артериального давления, частоты сердечных сокращений и частоты дыхания) свидетельствует об успешной адаптированности пациентов с ампутацией нижних конечностей к протезам.

На третьем этапе исследования для того, чтобы определить, у какой группы пациентов с ампутацией нижних конечностей применение БОСтренинга при адаптации к использованию протезов является наиболее эффективным, решалась задача оценки значимости различий показателей общей и болевой чувствительности, а также физиологических реакций после завершения курса занятий с использованием аппарата БОС у трех групп пациентов между собой методом попарного сравнения. 
Таблица 2

Показатели значимости различий показателей общей и болевой чувствительности, а также физиологических проявлений по группам испытуемых до и после экспериментального воздействия (критерий $\chi^{2}$ Фридмана, $\mathrm{p}<0,05$ )

\begin{tabular}{|c|c|c|c|c|}
\hline & \multirow{2}{*}{ Параметры } & \multicolumn{3}{|c|}{ Группы испытуемых } \\
\hline & & $Э_{1}$ & $\ni_{2}$ & $\mathrm{~K}$ \\
\hline \multirow{7}{*}{ 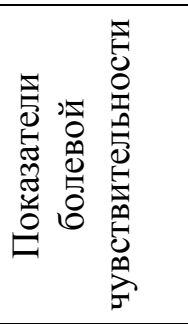 } & Нижний абсолютный порог болевых ощущений & $0,013 *$ & $0,041 *$ & $0,037 *$ \\
\hline & Субъективная оценка интенсивности болевых ощущений & $0,021 *$ & $0,008 *$ & $0,040 *$ \\
\hline & Дескрипторы интрацептивных ощущений & $0,024^{*}$ & $0,015^{*}$ & $0,025^{*}$ \\
\hline & Болезненные ощущения & $0,016^{*}$ & $0,027 *$ & $0,014 *$ \\
\hline & Опасные угрожающие здоровью ощущения & $0,037 *$ & $0,014 *$ & $0,003 *$ \\
\hline & Важные значимые ощущения & $0,030^{*}$ & $0,014 *$ & $0,036^{*}$ \\
\hline & Часто встречающиеся ощущения & $0,012 *$ & $0,029^{*}$ & $0,012 *$ \\
\hline \multirow{4}{*}{ 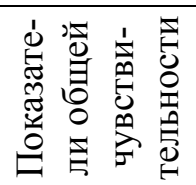 } & Локализация прикосновений & $0,034 *$ & $0,040^{*}$ & $0,014 *$ \\
\hline & Перенос прикосновений & $0,031 *$ & $0,026^{*}$ & $0,009 *$ \\
\hline & Одновременное прикосновение & $0,027^{*}$ & $0,015^{*}$ & $0,012 *$ \\
\hline & Дискриминационная чувствительность & $0,016^{*}$ & $0,029 *$ & $0,031^{*}$ \\
\hline \multirow{3}{*}{ 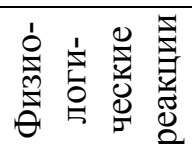 } & Артериальное давление & $0,029 *$ & $0,037 *$ & $0,035^{*}$ \\
\hline & Частота сердечных сокращений & $0,015^{*}$ & $0,020^{*}$ & $0,012 *$ \\
\hline & Частота дыхания & $0,014^{*}$ & $0,011^{*}$ & $0,044 *$ \\
\hline
\end{tabular}

Примечание: *-статистически значимые различия.

Таблица 3

Показатели долевого распределения пациентов с ампутацией нижних конечностей по показателям субъективной оценки интенсивности болевых ощущений после БОС-тренинга

\begin{tabular}{|l|c|c|c|c|c|c|}
\hline \multirow{2}{*}{ Качественно-количественная оценка } & \multicolumn{2}{|c|}{$Э 1$} & \multicolumn{2}{c|}{ Э2 } & \multicolumn{2}{c|}{ К } \\
\cline { 2 - 7 } & $\%$ & $\mathrm{x} \pm \sigma$ & $\%$ & $\mathrm{x} \pm \sigma$ & $\%$ & $\mathrm{x} \pm \sigma$ \\
\hline Сильная боль (6-8 баллов) & 87 & $5,67 \pm 1,30$ & 94 & $5,98 \pm 1,03$ & 85 & $5,79 \pm 1,12$ \\
\hline Очень сильная, нестерпимая боль (9-10 баллов) & 13 & $7,92 \pm 1,16$ & 6 & $7,36 \pm 2,04$ & 15 & $7,15 \pm 1,86$ \\
\hline
\end{tabular}

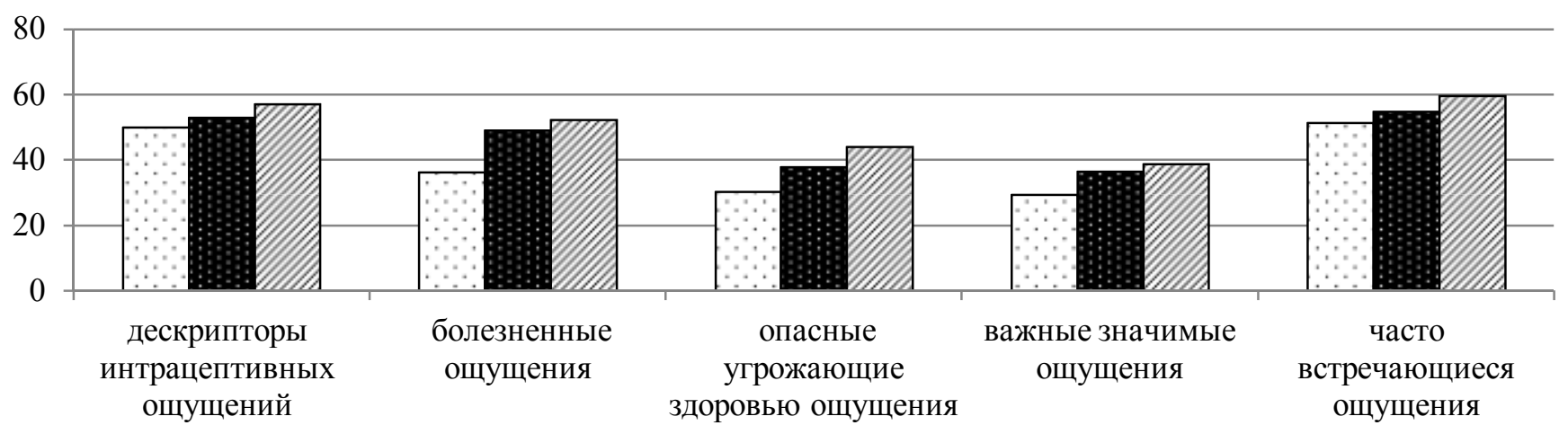

๑ациенты с ампутацией неведущей ноги

в Пациенты с ампутацией ведущей ноги

๑ Пациенты с ампутацией обеих нижних конечностей

Рис 3. Гистограмма частот значений дескрипторов интрацептивных ощущений у пациентов с ампутацией нижних конечностей после БОС-тренинга.

Осуществляя объективную оценку порога болевой чувствительности, установлено, что у пациентов с ампутацией неведущей ноги значения нижнего абсолютного порога болевой чувствительности значимо ниже по сравнению с пациентами с ампутацией обеих нижних конечностей $(\mathrm{p}=0,029)$ и значимо выше в сравнении с пациентами с ампутацией ведущей ноги $(\mathrm{p}=0,024)$.

При исследовании субъективной оценки интенсивности болевых ощущений у пациентов с ампутацией нижних конечностей выявлено изменение только количественной оценки без изменения качественной. У всех испытуемых преобла- 
дающей является сильная боль, соответствующая в количественном выражении 5-7 баллам (таблица 3$)$.

Максимальное снижение показателей субъективной оценки интенсивности болевых ощущений выявлено у пациентов с ампутацией неведущей ноги как в сравнении с пациентами с ампутацией ведущей ноги $(\mathrm{p}=0,012)$, так и в сравнении с пациентами с ампутацией обеих ног $(\mathrm{p}=0,037)$.

При исследовании дескрипторов интрацептивных ощущений у пациентов с ампутацией нижних конечностей по трем группам выявлено значимое снижение количества всех видов дескрипторов (рисунок 3).

Общее количество дескрипторов интрацептивных ощущений значимо выше у пациентов с ампутацией обеих нижних конечностей как в сравнении с пациентами с ампутацией ведущей ноги $(\mathrm{p}=0,029)$, так и в сравнении с пациентами с ампутацией неведущей ноги $(\mathrm{p}=0,024)$. При этом количество дескрипторов интрацептивных ощущений у пациентов при ампутации ведущей и неведущей ноги значимо не отличается $(\mathrm{p}=0,069)$.

При анализе лингвосемантического означивания болевых ощущений у пациентов с ампутацией нижних конечностей выявлено значимое увеличение частот лингвосемантических единиц сенсорного ощущения боли и снижение частот эмоционального отношения к боли у пациентов с ампутацией неведущей ноги как в сравнении с пациентами с ампутацией ведущей ноги $\left(\mathrm{p}_{1}=0,026\right.$; $\left.\mathrm{p}_{2}=0,032\right)$, так и в сравнении с пациентами с ампутацией обеих нижних конечностей $\left(\mathrm{p}_{1}=0,012\right.$; $\left.\mathrm{p}_{2}=0,027\right)$. При этом по критерию сенсорного ощущения боли у пациентов с ампутацией неведущей ноги преобладают зудящие, дергающие и жгучие боли; у пациентов с ампутацией ведущей ноги преобладает ноющая, монотонная и поверхностная боль; у пациентов с ампутацией обеих нижних конечностей преобладают зудящие и глубинные ощущения боли. По критерию эмоционального отношения к боли профиль лингвосемантического означивания характеризуется: у пациентов с ампутацией неведущей ноги преобладанием беспокоящей и надоедливой боли; у пациентов с ампутацией ведущей ноги мешающей, угнетающей и истязающей боли; у пациентов с ампутацией обеих нижних конечностей преобладанием мучающей, терзающей, тягостной и истязающей боли.

При исследовании экстероцептивной чувствительности у пациентов с ампутацией нижних конечностей получены результаты, указывающие на значимое снижение чувствительности у пациентов с ампутацией неведущей ноги в сравнении с пациентами, у которых ампутирована ведущая нога ( $\mathrm{p}=0,022)$, а также у пациентов с ампутацией ведущей ноги в сравнении с пациентами с ампутацией обеих нижних конечностей $(p=0,009)$. При исследовании локализации прикосновений установлено, что у пациентов с ампутацией неведущей ноги границы точности локализации прикосновений соответствуют 10-15 мм в 73,9\% случаев; у пациентов с ампутацией ведущей ноги определяется в тех же границах у 69,4\% пациентов; у $61,2 \%$ пациентов с ампутацией обеих нижних конечностей точность локализации прикосновений также определяется в границах 10-15 мм. При исследовании переноса прикосновений, дифференциации двух прикосновений одновременно и дискриминационной чувствительности статистически значимых различий при попарном сравнении трех групп испытуемых не выявлено.

В результате исследования показателей физиологических реакций у пациентов с ампутацией нижних конечностей выявлено значимое снижение по всем показателям у пациентов с ампутацией неведущей ноги в сравнении как с пациентами с ампутацией ведущей ноги, так и в сравнении с пациентами с ампутацией обеих нижних конечностей (рисунок 4).

Полученные результаты указывают на то, что применение БОС-тренинга позволяет снизить как общую, так и отдельно болевую чувствительность у пациентов с ампутацией нижних конечностей (c ампутацией ведущей ноги, неведущей ноги, обеих нижних конечностей), повысив порог болевой чувствительности. Снижение субъективной оценки болевых ощущений на уровне лингвосемантического означивания проявляется в повышении дифференцированности дескрипторов сенсорного ощущения боли при снижении дифференцированности эмоциональной оценки болевых ощущений по всем группам пациентов с ампутацией нижних конечностей.

Применение биологической обратной связи как технологии адаптации к использованию протезов при ампутации нижних конечностей позволяет повысить эффективность социального функционирования данной категории пациентов.

\section{ЛИТЕРАТУРА}

1. Вассерман Л.И., Дорофеева С.А., Меерсон Я.А. Методы нейропсихологической диагностики. М. : Изд-во Стройлеспечать, 1997. - 360 с.

2. Ершова И.Б., Иванов А.С., Шалимов С.А., Прихода Д.В., Устиченко Е.П., Молодых Д.А., Уткин Д.О. Фантомно-болевой синдром - реальная проблема, стоящая перед человеком с ампутированной конечностью // Таврический медикобиологический вестник. - 2012. - Т. 15, № 3, Ч. 2 (59). - C. 97-99. 
Показатели физиологических реакций до проведения БОС-тренинга

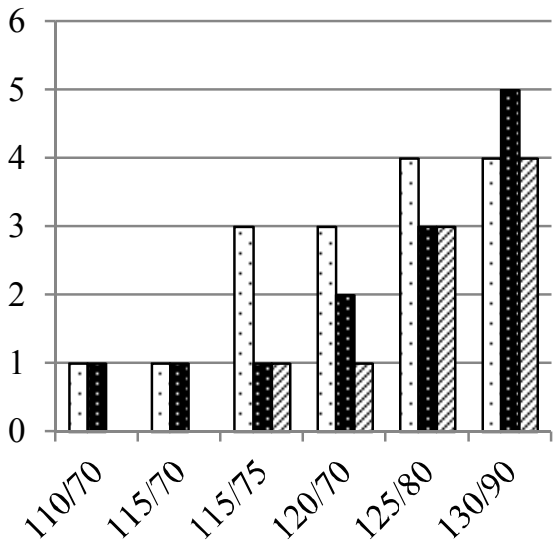

Показатели артериального давления (мм рт. ст.)

๑1 •Э2 ๒К

A

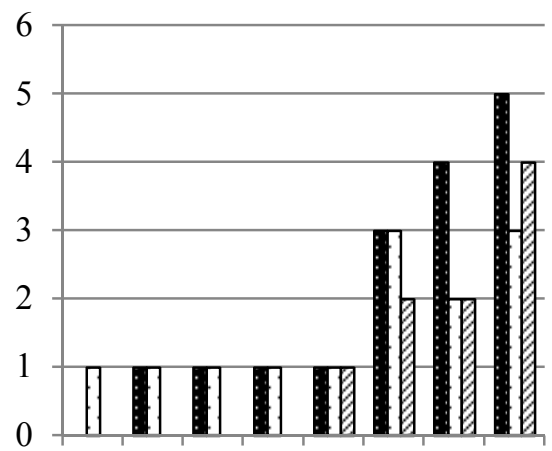

$\begin{array}{llllllll}74 & 75 & 80 & 83 & 88 & 90 & 92 & 94\end{array}$

Частота сердечных сокращений

(кол-во ударов в мин)

•Э1 ロЭ2 घК

$\mathrm{B}$

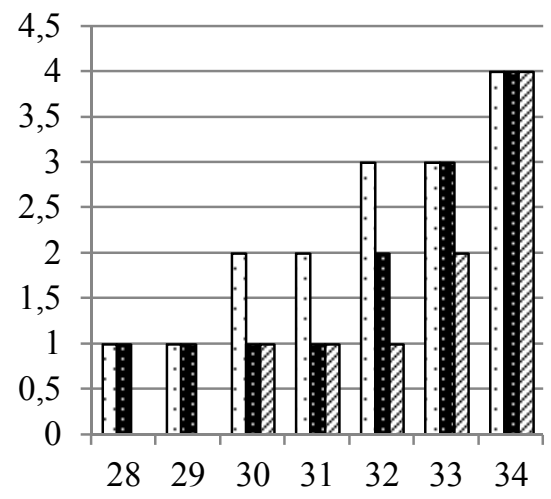

Частота дыхания (кол-во вдохов в мин)

๑1 •Э2 ๒К

Показатели физиологических реакций после проведения БОС-тренинга

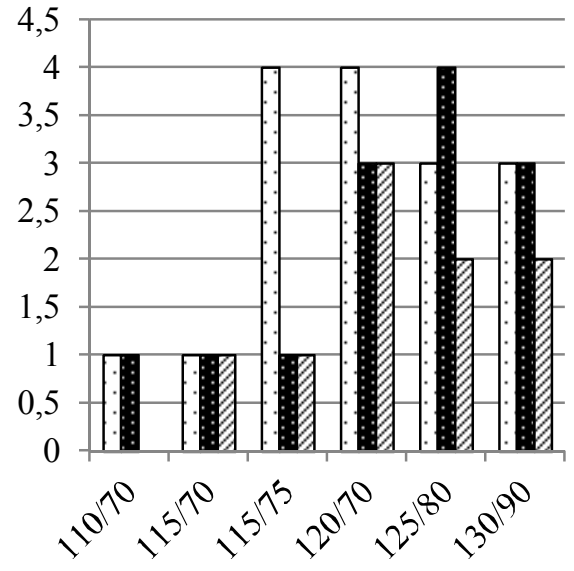

Показатели артериального давления (мм рт. ст.)

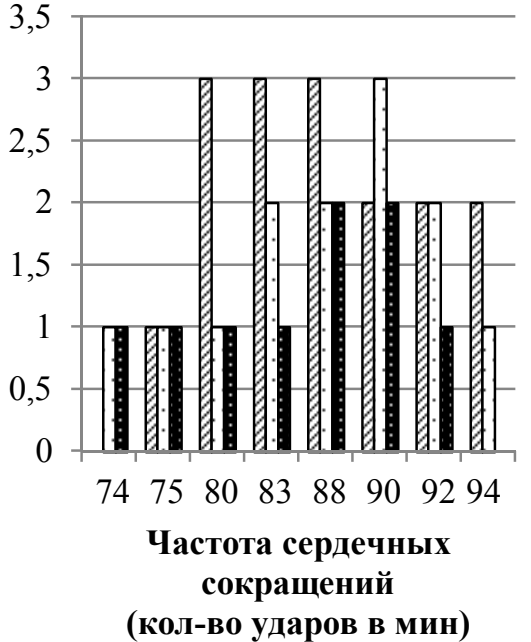

๒Э1 ๑Э2 $\mathbf{⿴ K}$

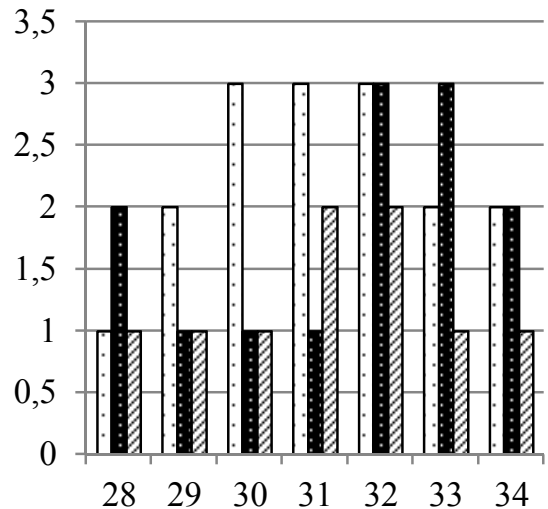

Частота дыхания (кол-во вдохов в мин)

$\square Э 1 \cdot Э 2 \square \mathrm{K}$

$\mathrm{C}$

A

B

Рис. 4. Гистограммы частот показателей физиологических реакций у пациентов с ампутацией нижних конечностей до и после БОС-тренинга.

3. Ииинова В.А., Поворинский А.А., Митякова О.Н. Изменение порогов тактильной чувствительности при фантомной боли у пациентов, перенесших ампутацию нижних конечностей // Российский журнал боли. - 2014. - № 1 (42). - С. 77.

4. Никишина В.Б., Бобыниев И.И., Петраш Е.А., Миняхина K.A. Дескрипторы интрацептивных ощущений при фантомно-болевом синдроме у людей с ампутацией нижних конечностей // Курский научно-практический вестник «Человек и его здоровье». - 2015. - № 3. - С. 133-139.

5. Никишина В.Б., Иванова Н.Л., Петраш Е.А., Ахметзянова А.И. Нарушение схемы тела при ампутации нижних конечностей // Курский научно-практический вестник «Человек и его здоровье». - 2016. - № 4. - С. 124-131.

6. Попова Г.В. Коррекция статокинетической устойчивости лиц, перенесших ампутацию нижних конечностей, на этапе протезирования // Вестник спортивной науки. - 2014. - № 6. - С. 42-45.

7. Рукина Н.Н., Белова А.Н., Кузнецов А.Н., Борзиков B.B. Влияние темпа на биомеханические параметры ходьбы здоровых и пациентов с разным уровнем ампутации нижней конечности // Российский журнал биомеханики. - 2016. - Т. 20, № 1. - С. 58-69.

8. Скляренко Р.Т., Дотдуев С.Х., Спиридонова В.С. Возможности реинтеграции в нормальную жизнь больных с ампутацией нижних конечностей при 
атеросклерозе // Медико-социальная экспертиза и реабилитация. - 2014. - Т. 17, № 4. - С. 47-48.

9. Тхостов А.Ш., Елианский С.П. Методическое пособие по применению теста «Выбор дескрипторов интрацептивных ощущений» для исследования особенностей вербализации внутреннего опыта. М. : Изд-во МГУ, 2003. - 24 с.

10. Dahlöf $B$. Cardiovascular disease risk factors: epidemiology and risk assessment // Am.
J. Cardiol. - 2010. - Vol. 105, N 11, Suppl. 1. P. 3A-9A. - doi: 10.1016/j.amjcard.2009.10.007.

11. Huskisson E.C. Measurement of pain // Lancet. 1974. - Vol. 304, Issue 7889. - P. 1127-1131.

12. Jivegard L.E.H. The development of a VBHOM-based outcome model for lower limb amputation performed for critical ischemia // Eur. J. Vasc. Endovasc. Surg. 2009 - Vol. 37, N 1. - P. 67. - doi: 10.1016/j.ejvs.2008.10.008. 